\title{
A produção de narrativas históricas de alunos do ensino fundamental: Um estudo exploratório
}

Osvaldo Rodrigues JÚNIOR"

\section{RESUMO}

Os objetivos traçados para o presente trabalho foram: i) analisar a produção de narrativas históricas de jovens do ensino médio, a partir do conteúdo proposto e da utilização de um documento histórico; ii) consolidar a proposta de professorpesquisador. Essa atividade foi desenvolvida com alunos do $6^{\circ}$ ano do Ensino Fundamental de um Colégio Público, em Curitiba. 0 tema escolhido foi à Imigração para o Brasil nos séculos XIX eXX. Metodologicamente, o trabalho foi divido em três etapas. A primeira, de aplicação dos conhecimentos prévios aos alunos. A segunda etapa foi a de intervenção nas idéias históricas dos alunos, e a terceira, a aplicação do instrumento de metacognição, a qual possibilitou uma comparação com os conhecimentos previamente identificados. Este estudo exploratório está inserido no debate sobre a relação entre a Didática Específica e a ciência de referência, e também naperspectiva daEducação Histórica. Conclui-se que o presente trabalho foi importante como experiênciaempírica de utilização de uma concepção de ensino aprendizagem referenciada na Educação Históricae na ciência de referência, ecentrada nos elementos da cognição históricasituada; também que, os resultados qualitativamente analisados demonstraram a possibilidade dos jovens alunos pensarem historicamente por meio da intervenção nas idéias históricas previamente verificadas.

Palavras-chave: Educação Histórica, Didática da História, Narrativas históricas.

\section{Introdução}

0 trabalho de Prats (2002) aponta questões que têm permitido discutir a Didática da História como um campo de pesquisa específico. Segundo Schmidt (2008), baseando-se em questões contemporâneas acerca dos paradigmas das

\footnotetext{
Mestrando em Educação do Programa de Pós-Graduação em Educação da Universidade Federal do Paraná. Orientado pela Profa: Dra. Maria Auxiliadora Moreira dos Santos Schmidt. Bolsista CNPQ. Email: osvaldo.rjunior@gmail.com.
} 
ciências, este autor parte do pressuposto de que o alargamento das possibilidades de se conhecer cientificamente o social tornou possível que vários aspectos da realidade se mostrem como foco de observação, ação e conhecimento científico. Neste aspecto, pode-se falar em novos campos da atividade científica, sendo a didática de uma determinada disciplina, no caso a História, uma possível demarcação da atividade de investigação. Ademais, em seu trabalho, Prats (2002) indica que uma das situações em que a relação de investigação da Didática da História vem se colocando deriva das experiências que são realizadas pelos docentes, e têm constituído um conjunto de conhecimentos acerca da realidade do ensino e aprendizagem da História.

Portanto, este estudo exploratório referenciado em uma perspectiva de que a relação entre a Didática da História e a ciência de referência, é fundamental para a constituição de uma aprendizagem cognitivamente situada. Nesse sentido, entende-se a Didática da História centrada nos pressupostos da Educação Histórica. A respeito disso, Rüsen (2007) afirma que o conceito de Didática possui na História um sentido controverso. De um lado possui uma "venerável tradição" fundada antes da cientificização, enquanto hoje ocupa um lugar externo a ciência específica. Nesse sentido, "os didáticos seriam transportadores, tradutores, encarregados de fornecer ao cliente ou à cliente - comumente chamado de "aluno" ou "aluna" - os produtos científicos" (RÜSEN, 2007. p. 89). Essa visão, por mais que seja dominante em relação aos especialistas hoje, dificilmente é fundamentada pelos mesmos, sendo que esta "externalização e funcionalização da didática são o reflexo de uma concepção estreita de ciência, por parte dos historiadores profissionais" (RÜSEN, 2007. p. 89).

De um lado é nesse espectro de investigações que se inserem as reflexões desse trabalho, o qual apresenta um conjunto de reflexões sistematizadas a partir de experiência desenvolvida com jovens alunos do ensino fundamental de um colégio público, na cidade de Curitiba-PR. De outro, o trabalho inscrevese no conjunto de experiências e reflexões do campo da Educação Histórica, na medida em que procura analisar as idéias históricas de jovens alunos, a partir da produção de narrativas históricas. Nessa direção, o trabalho apresenta uma investigação realizada numa escola de ensino fundamental de Curitiba. 


\section{Narrativa e ensino de História}

Rüsen (2001) afirma que a História é uma ciência fundamentalmente narrativa, sendo que o pensamento histórico obedece a uma lógica narrativa. Partindo desse pressuposto, o autor diferencia a narrativa histórica da narrativa ficcional mediante três características específicas: a) as narrativas históricas mobilizam experiências passadas; b) as narrativas históricas possuem organização através das três dimensões temporais - passado, presente e futuro; c) as narrativas históricas possuem a idéia de continuidade.

Desta forma, o ato de narrar é um tipo de explicação racional, pois "a racionalidade do pensamento histórico pode ser descrita como um modo de constituição de sentido que consiste na forma de comunicação de raciocínio argumentativa" (RÜSEN, 2001. p. 154). Portanto, entende-se ainda que, para a narrativa histórica é fundamental que ela se vincule a experiência no tempo, de maneira que o passado sirva de orientação da vida prática ganhando assim status de "história".

Como afirma Silva (1984) o professor de História possui uma imagem tradicional de "narrador de histórias", porém, histórias essas diferentes das estórias sem o status científico. Ademais, é preciso desmistificar essa idéia de que apenas o professor de História produz narrativas históricas, sendo está à principal questão desta investigação, os alunos, sujeitos dos processos de escolarização, também produzem narrativas históricas?

\section{Investigação e análise dos conhecimentos prévios dos alunos}

A aplicação dos conhecimentos prévios aos alunos ocorreu no dia 15 de maio de 2007. A turma escolhida, $06^{\circ}$ ano do ensino fundamental, era composta por 32 alunos, porém, naquela data compareceram apenas 18 alunos. Tendo como perspectiva de investigação a educação histórica entende-se que:

A intervenção começa com o levantamento informal de idéias tácitas dos participantes acerca da História e de modelos de aprendizagem e práticas de aula: desenvolve-se com a implementação de experiências de sala de aula, em pequenas equipas, e termina com um relatório acompanhado de exercício de reflexão metacognitiva. (BARCA, 2007, p.34-35). 
Assim sendo, a metodologia utilizada para esta investigação partiu da aplicação de um questionário, contendo três perguntas com respostas descritivas sobre o tema Imigração para o Brasil nos séculos XIX e XX, conteúdo escolhido de acordo com as Diretrizes Curriculares do Estado do Paraná para o Ensino de História no Ensino Fundamental (2008).

A primeira pergunta procurou identificar como era o entendimento dos alunos sobre o conceito de Imigração; a segunda pergunta procurou investigar como os alunos realizavam a localização temporal do movimento imigratório a ser trabalhado em sala de aula; e a terceira questão procurou observar como os alunos elaboravam seu conhecimento das causas que geraram esse movimento imigratório.

As três tabelas abaixo apresentam a síntese das respostas, com destaque para aquelas com resultados mais significativos.

Questão 1 - Como você entende o conceito imigração?

\begin{tabular}{|l|l|}
\hline Pessoa que imigra de um país para outro & 12 respostas $-66,8 \%$ \\
\hline Entrar em um país sem permissão & 2 respostas $-11,1 \%$ \\
\hline Migrar de um estado ou região para o outro & 2 respostas $-11,1 \%$ \\
\hline Movimento colonizador & 1 respostas $-5,5 \%$ \\
\hline Comercialização de escravos & 1 resposta $-5,5 \%$ \\
\hline
\end{tabular}

Questão 2 - Quando você acredita que os imigrantes vieram para o Brasil?

\begin{tabular}{|l|l|}
\hline $\begin{array}{l}\text { Imigração como movimento colonizador ou em } \\
1500 .\end{array}$ & 6 respostas $-33,8 \%$ \\
\hline 1.600 & 1 resposta $-5,5 \%$ \\
\hline Durante o reinado de D.Pedro II & 1 resposta $-5,5 \%$ \\
\hline Durante o período de independência & 1 resposta $-5,5 \%$ \\
\hline Há 500 anos atrás & 1 resposta $-5,5 \%$ \\
\hline Quando se aboliu a escravidão & 3 respostas $-16,6 \%$ \\
\hline 1850 & 2 respostas $-11,1 \%$ \\
\hline
\end{tabular}




\begin{tabular}{|l|l|}
\hline Durante o reinado de D.Pedro I & 1 resposta $-5,5 \%$ \\
\hline Nem imagino & 1 resposta $-5,5 \%$ \\
\hline 1800 & 1 resposta $-5,5 \%$ \\
\hline
\end{tabular}

Questão 3 - Porquê você acha que os imigrantes vieram ao Brasil?

\begin{tabular}{|l|l|}
\hline A procura de trabalho. & 5 respostas - $27,7 \%$ \\
\hline Mudar de vida, fugir das condições de vida anteriores. & 5 respostas $-27,7 \%$ \\
\hline $\begin{array}{l}\text { Em busca de matéria prima e terras para serem } \\
\text { trabalhadas. }\end{array}$ & 6 respostas $-33,6 \%$ \\
\hline Para comprar terra e consumir produtos. & 1 resposta $-5,5 \%$ \\
\hline $\begin{array}{l}\text { Para fazer confusão e conseguir votos para ser } \\
\text { presidente da província }\end{array}$ & 1 resposta -5,5\% \\
\hline
\end{tabular}

Partindo da tabulação dos conhecimentos prévios, observa-se nas respostas da primeira questão não ser necessária uma conceituação de Imigração, pois para a maioria dos alunos está claro que imigração é um movimento que se faz de um país para outro. Porém, Rüsen (2007) diferencia os conceitos históricos, dos nomes próprios e das categorias históricas. Os conceitos são "históricos", quando se referem ao estado das coisas tendo a ciência como referência. Desta forma, dão qualidade temporal ao estado de coisas numa relação de sentido e significado entre passado, presente e futuro.

Existem conceitos como "economia", "trabalho", "constituição", que não são conceitos históricos, mas sim "conceitos-gêneros" como designou Max Weber (Apud: RÜSEN, 2007. p. 92). São conceitos comuns a vários estados de coisas, que passam a ser históricos a partir do momento em que dão qualidade temporal a esse estado de coisa, como por exemplo: "economia feudal" e "camponês na Inglaterra do século XVII".

$\mathrm{Na}$ questão dois observa-se a importância de, no sentido empregado por Peter Lee (2005) dar "substância" aos conceitos, pois "é importante lembrar que entender conceitos - tais como colônia, mercado ou imigração - envolve conhecer uma regra (o que faz algo ser imigração, por exemplo) e ser capaz de identificar exemplos daquela regra" (LEE, 2005. p. 1). Dessa forma, desfazer a confusão histórico-temporal, explícita nas respostas dos alunos entre 0 
movimento colonizador português e o movimento imigratório nos séculos 19 e 20, teve como objetivo principal diferenciar: nomes próprios entendidos como, "estados de coisas do passado em sua ocorrência singular" (RÜSEN, 2007. p. 93); categorias históricas entendidas como "contextos temporais gerais de estados de coisas, com base nos quais estes aparecem como históricos" (RÜSEN, 2007. p. 93); e os conceitos históricos entendidos como "estados de coisas referidos por nomes próprios, as qualidades históricas pré-esboçadas pelas categorias históricas" (RÜSEN, 2007. p. 94).

Com relação à questão três observa-se o mesmo problema da questão dois, a confusão entre os movimentos de Imigração colonizadora e o movimento Imigração iniciado no século 19. Nessa questão, os alunos fazem certa confusão no objetivo da vinda dos imigrantes. Apesar de 55,4\% dos alunos compreenderem, com certa correção, o objetivo como procura por emprego e tentativa de mudança de vida, 33,3\% dos alunos ainda relacionam de maneira confusa o objetivo da vinda dos imigrantes. Para eles, o objetivo era a procura por terras férteis e matérias primas.

\section{Descrição da intervenção}

A partir da análise dos conhecimentos prévios, a segunda aula no dia 5 de junho de 2007 foi utilizada para discutir o "conceito substantivo", a imigração para o Brasil nos séculos 19 e 20, por intermédio da diferenciação entre 0 movimento imigratório colonizador e o movimento imigratório dos séculos 19 e 20. Dessa forma, buscou-se intervir nas "idéias históricas restritas" (BARCA, 2007. p. 35), entendidas como, noções menos válidas em termos de conhecimentos históricos dos alunos. Ademais, a partir das referências historiográficas, criou-se um quadro de diferenciação a ser discutido com os alunos em sala de aula. 


\begin{tabular}{|l|l|}
\hline Movimento de imigração colonizadora & $\begin{array}{l}\text { Movimento de imigração povoador e de } \\
\text { suprimento de mão de obra }\end{array}$ \\
\hline Marco temporal: Século 16 & Marco temporal: Século 19-20 \\
\hline $\begin{array}{l}\text { Caracterização: Movimento de descobrimento e } \\
\text { colonização }\end{array}$ & $\begin{array}{l}\text { Caracterização: Movimento de povoamento de } \\
\text { regiões ainda não povoadas e, principalmente de } \\
\text { suprimento da mão de obra escrava }\end{array}$ \\
\hline Nacionalidade dos imigrantes: Portugueses & $\begin{array}{l}\text { Nacionalidades dos imigrantes: Espanhóis, } \\
\text { Italianos, Portugueses, Alemães, Poloneses, } \\
\text { Ucranianos, Japoneses, Chineses e outros }\end{array}$ \\
\hline Importância: Descobrimento do Brasil, assim como & $\begin{array}{l}\text { Importância: Primeiro ciclo (50 anos iniciais) - } \\
\text { povoar alguns territórios não povoados ou pouco } \\
\text { povoados. Segundo ciclo - Suprimento da mão-de- } \\
\text { obra em falta após a proibição do tráfico e abolição } \\
\text { da escravidão. }\end{array}$ \\
\hline
\end{tabular}

A última aula, no dia 12 de junho de 2007, serviu para uma análise da iconografia utilizando-se as fotografias mais representativas do movimento imigratório dos séculos 19 e 20, para se fazer um paralelo com a iconografia atual. 0 objetivo foi demonstrar os traços culturais e arquitetônicos dos imigrantes na formação da sociedade brasileira, fazendo a relação histórica fundamental entre presente e passado, para que o "conceito substantivo" tornese um elemento de

um grande quadro organizado por conceitos substantivos sobre os quais eles, de modo crescente, entendem e podem refletir. Isto também significa que eles também precisam de um conhecimento aprofundado de passagens (não demasiado longas) contidas no passado, com tempo para explorar o jeito de vida e a visão de mundo das pessoas que estão estudando (LEE. 2005. p. 8)

A intenção foi a de que os alunos, por intermédio da utilização do "conceito substantivo", Imigração para o Brasil nos séculos 19 e 20 conseguissem se orientar temporalmente. Dessa forma, foram desenvolvidos os exercícios de metacognição, que se basearam na produção de uma narrativa histórica a partir da leitura de um documento histórico, um certificado de identificação de um imigrante português; e também de um exercício de chuva de idéias com relação à palavra imigração. 


\section{Resultados apresentados na aplicação do instrumento de metacognição}

Utilizando uma perspectiva qualitativa de análise dos dados, entende-se que os alunos, sujeitos principais dos processos de escolarização, produziram narrativas históricas a partir do trabalho de intervenção do professor-pesquisador, objetivo do presente trabalho.

Desta forma, certos exemplos de narrativas possuem maior "sofisticação", como afirma Gago (2007), em seu estudo sobre as concepções de alunos entre os 10 e 14 anos, a respeito da variância da narrativa histórica.

A partir disso, destacam-se algumas narrativas apresentadas a seguir: Aluno 1:

Ele veio para o Brasil, deixando toda a sua família: pais amigos e colegas. Deixou Portugal e veio aqui para a imigração. Construiu vários monumentos, lembranças de Portugal ele trouxe pra cá e deixou marcas. Ele veio para o Brasil fugindo das guerras e confusões, com medo de morrer. Veio ao Brasil em 26 de maio de 1936 e nasceu em 22 de abril de 1883. Os nomes dos pais dele eram: Francisco Domingues e Anna Esteves. Foram esses que ele deixou em Portugal. Mas no Brasil ele não se deu muito bem, mas também houve felicidades, teve uma família aqui.

Aluno 2:

Manoel Joaquim Dominguez veio de Melgaço Portugal veio em busca de uma vida melhor no Brasil "fugir" das dificuldades. Ele acabou com o seu sonho, logo quando viu as pessoas de natalidades diferentes trabalhando como escravos. Existia muita falta de higiene, pouco espaço para dormir e muita fome. Era a verdadeira escravidão.

\section{Aluno 3:}

Manoel Joaquim Domingues nasceu em 22 de abril de 1883, ele era filho de Francisco Domingues e Anna Esteves morava em Melgaço Portugal, ele era português, ele tinha cor branca, a cor dos seus olhos era castanho escuro e a de seus cabelos era gris.

Barca (2007) afirma que as leituras consubstanciadas do passado em forma de narrativa expressam a consciência histórica, e utilizando Rüsen, 
afirma que existem quatro tipologias de narrativas históricas: a tradicional (afirmação de determinadas orientações temporais); a exemplar (regularidade de padrões culturais); a crítica (desses padrões); e a genética (transformação dos padrões em orientações específicas).

Por exemplo, na narrativa histórica do aluno 1 , aparecem características da narrativa tradicional: "veio ao Brasil em 26 de maio de 1936 e nasceu em 22 de abril de 1883", pois nesta passagem o aluno se orienta temporalmente de maneira "superficial" ao retirar apenas informações contidas no documento, porém sem fazer relação histórica com o conteúdo trabalho; 0 aluno 2, por sua vez, constrói uma narrativa histórica crítica, a afirmar que "ele acabou com o seu sonho, $\log 0$ quando viu as pessoas de natalidades diferentes trabalhando como escravos. Existia muita falta de higiene, pouco espaço para dormir e muita fome. Era a verdadeira escravidão", desta forma, o aluno faz uma crítica dos padrões de vida dos imigrantes, comparando dois modos de produção diversos: 0 trabalho escravo, e 0 trabalho assalariado; Enquanto que 0 aluno 3 constrói uma narrativa histórica tradicional, pois assim como 0 aluno 1 apenas retira informações do documento, não fazendo as relações entre a experiência e o conhecimento histórico: "nasceu em 22 de abril de 1983 ele era filho de: Francisco Domingues e Anna Esteves, morava em Melgaço Portugal,ele era português, ele tinha cor branca, a cor dos seus olhos era castanho escuro e a de seus cabelos era gris".

Por fim, desenvolveu-se um exercício de chuva de idéias relacionado ao conceito de imigração.

Escreva 5 palavras que você relaciona com 0 tema imigração.

\begin{tabular}{|l|l|l|l|}
\hline Escravidão-32\% & Falta de Comida - 23\% & Brasil - 3\% & Liberdade - 1,5\% \\
\hline Falta de Higiene - 29\% & Imigrantes - 3\% & Branquear - 1,5\% & Outros - 7\% \\
\hline
\end{tabular}

No caso da chuva de idéias, uma característica marcante foi à crítica das condições de vida que os imigrantes encontraram no Brasil, elemento trabalhado em exaustão, tanto pela historiografia, como em sala de aula. Porém os resultados, ao mesmo tempo em que apontam os limites de uma experiência de estágio, demonstram a importância da concepção do professorpesquisador, de que ele deve ser investigador das "necessidades cognitivas específicas" dos seus alunos, sujeitos principais dos processos de escolarização. 
Concluindo, entende-se que "controlar o passado ajuda a dominar o presente, a legitimar tanto as dominações como as rebeldias" (FERR0, 1983. p. 11). Portanto, as investigações em ensino e aprendizagem da História na perspectiva da educação histórica têm demonstrado resultados na direção da construção de tipos de consciência histórica, entendendo-se que está transformada em "contra-internalização", pode demonstrar como:

o papel da educação é soberano, tanto para elaboração de estratégias apropriadas e adequadas para mudar as condições objetivas de reprodução, como para a automudança consciente dos indivíduos chamados a concretizar a criação de uma ordem social metabólica radicalmente diferente. (MÉSZÁROS, 2005. p. 65).

\section{Referências}

BARCA, I. Investigação em Educação Histórica: possibilidades e desafios para a aprendizagem histórica. In: SCHMIDT, M. A; GARCIA, T. M. F. B. (orgs). Perspectivas de investigação em educação histórica: atas das VI jornadas internacionais de educação histórica. vol. 1. Curitiba: Editora da Universidade Tecnológica Federal do Paraná, 2007. p. 26-42.

FERRO, M. A manipulação da bistória no ensino e nos meios de comunicação. São Paulo: Ibrasa, 1983.

GAGO, Marília. Um olhar acerca da multiperspectiva em História: idéias de alunos entre os 10 e os 14 anos. In: SCHMIDT, M. A; GARCIA, T. M. F. B (orgs). Perspectivas de investigação em educação bistórica: atas das VI jornadas internacionais de educação bistórica. vol. 1. Curitiba: Editora da Universidade Tecnológica Federal do Paraná, 2007. p 68-88.

LEE, P. Putting principles into practice: understanding history. In: BRANSFORD, J. D.; DONOVAN, M. S. (Eds.). How students learn: history, math and science in the classroom. Washington, DC: National Academy Press, 2005. Disponível em $<\underline{\text { http://aim.psch.uic.edu/ }}$ courses/aim/lesson.asp?idCourseLesson=836 > Acesso em 25 de julho de 2008.

MÉSZÁROS, I. A educação para além do capital. São Paulo: Boitempo, 2005.

PRATS, J. Hacia uma definición de la investigación em didáctica de lãs ciências sociales. In: Enseñanza de lãs ciências sociales: revista de investigación, Barcelona, $\mathrm{n}^{\circ} .1, \mathrm{p}$. 81-89, março/2002. 
RÜSEN, J. História viva. Brasília: UNB, 2007.

. Razão histórica. Brasília: UNB, 2001.

. Reconstrução do passado. Brasília: UNB, 2007.

SCHMIDT, M. A. Trajetórias da investigação em didática da História no Brasil: A experiência da Universidade Federal do Paraná. Disponível em <.http://www.ub.es/ histodidactica/> acesso em 15 de maio de 2008.

SILVA, M (org). Repensando a história. Rio de Janeiro: Marco Zero, 1984.

\section{The historicals narratives produced by the students of elementary school: a exploratory study}

Abstract

This paper aims to present the results of an exploratory study developed in the year 2007. The objectives outlined for this study were: i) examine the production of historical narratives of young high school from the proposed content and use of a historical document, ii) consolidate the proposed teacher-researcher. This activity was developed with students from 6th grade of elementary school from a public college in Curitiba. The chosen theme was the Immigration to Brazil in the XIX and XX centuries. Methodologically, the work was divided into three stages. The first was the application of student's previous knowledge. The second step was to intervene in historical ideas of students, and the third, the application of the metacognition instrument, which allowed a comparison with the knowledge previously identified. This exploratory study is inserted in the debate on the relationship between science and Teach Specific reference, and also in terms of Historical Education, arguing that "these studies, researchers have focused their attention on the principles, sources, types and strategies for learning Historian, under the assumption that the intervention in the quality of learning requires a systematic knowledge of the historical ideas of students, from those who teach (and also requires a knowledge of historical ideas of the latter)" (BARCA, 2005. p. 15). It follows that this work was as important empirical evidence of using a design of teaching and learning referenced in Education History and science of reference, and focusing on elements of the 
historic situated cognition; that, the qualitatively analyzed results demonstrated the feasibility of young students think historically through intervention in historical ideas previously discovered recorded.

Key-words: History Education, Didactical of History, Historical narratives. 